DOI 10.37882/2223-2982.2020.12.09

\title{
СТИЛИСТИЧЕСКИЕ ВОЗМОЖНОСТИ АНАФОРИЧЕСКОГО ПОВТОРА В РОМАНЕ ФРАНСУАЗЫ ЛЁФЕВР «МАЛЕНЬКИЙ ПРИНЦ -КАННИБАЛ»
}

\section{STYLISTIC POTENTIAL OF ANAPHORIC REPETITION IN THE NOVEL "LE PETIT PRINCE CANNIBALE" BY FRANÇOISE LEFÈVRE}

\section{Gorelik E. Novikova}

Summary: The article analyses the expresive potential of anaphora - the syntactic figure of speech in emotional expressiveness sense. As one of the figures of addition, anaphora is intended to emphasize the constancy of the author's feelings. And as one of the figures of ordered repetition, anaphora emotionally highlights individual parts of the text, creates the effect of the culmination of events.

Keywords: anaphoric repetition, anaphora functions, lexico-grammatical anaphora, contact anaphora, distant anaphora, anadiplosis, frame construction.

\author{
Горелик Маргарита Алексеевна \\ Старший преподаватель, Тихоокеанский \\ государственный университет, г. Хабаровск \\ ritagorelik@mail.ru \\ Новикова Елена Николаевна \\ Старший преподаватель, Тихоокеанский \\ государственный университет, г. Хабаровск
}

Аннотация: В статье предпринята попытка анализа выразительного потенциала синтаксической фигуры - анафорического повтора в экспрессивно-эмоциональном плане. Являясь одной из фигур прибавления, анафора призвана подчеркнуть постоянства испытываемых чувств автора и как одна из фигур упорядоченного повтора, эмоционально выделяет отдельные части текста, создаёт эффект кульминации событий.

Ключевые слова: анафорический повтор, функции анафоры, лексико-грамматическая анафора, контактная анафора, дистантная анафора, анадиплосис, рамочная конструкция.
$\mathrm{B}$ автобиографическом романе Франсуазы Лёфевр «Маленький принц -каннибал» повтор обеспечивает высокую эмоциональность повествования и детально отражает переживания автора-главной героини, женщины-писателя, не имеющей возможности, а иногда и потребности, желания писать, в силу обстоятельств, вынужденную всё своё время посвящять детям, в частности сыну, рождённому с синдромом Аспергера.

Mais, toi, aujourd 'hui, je te remercie de me donner la possibilité de vivre un grand amour. Je te remercie de $m$ 'avoir ouvert les yeux sur une part du monde et sur les autres enfants. Je te remercie de $m$ 'avoir fait violence, de $m$ `avoir presque tuée [1, c. 22].

В основе анафорического повтора может лежать звук, звукосочетание, морфема, слово, словосочетание, фраза, синтаксическая конструкция [5, с. 17; 6, с. 57]. В данном примере лексико-грамматическая контактная анафора- стилистическая фигура, подразумевающая повторение начальных частей, синтаксических конструкций в нескольких соседних предложениях, эмоционально выделяет чувства матери к сыну, с одной стороны, совершенно естественные, но с другой стороны, чувства выстраданные, прошедшие испытание психической болезнью ребёнка.
Сочетание в следующем примере лексико-грамматической анафоры, предложений неполного состава и супраграфемного средства выразительности, а именно употребление букв в верхнем регистре, придают абзацу сильную эмоциональную окраску, что является одной из основных функций анафоры [3, с. 94]:

Je ne te laisse jamais construire ta tour infernale. Je ne te laisse jamais t’y enfermer. Je n’ai pas lu d’ouvrage sur lautisme. Je sens leurs auteurs pessimistes. Défaitistes. Je ne veux pas qu' ils entament ma belle foi. Ma rage de vaincre. Je ne veux pas que tu sois un cas parmi d’autres, car pour moi tu es UNIQUE. [1, c.79].

Mes journées ne sont faites que de TOI. TOI.TOI.

Mais je trouve de la force dans cet amour que nous avons noué ensemble. Colchiques dans les prés. Je t’aime. Je t'aime [1, c. 52].

В следующих примерах лексико-грамматическая анафора помогает почувствовать решимость матери бороться с болезнью сына:

Il me semblait que tu n étais pas à ta place parmi ces malheureux gamins baveux, hébétés ou très agités. II me semblait que tu étais moins atteint qu`eux, ou l`amour maternel me rendait-il aveugle? [1, c. 21].

Il faut, Sylvestre, que j'accepte $d$ 'être moins exaspérée par tes cris de violence, ces ornières où tu tombes si souvent. Il faut que j'accepte de ne plus écrire, de remettre mon 
livre sans cesse à demain avec tout le malaise que cela fait naître en moi. /l faut que j 'accepte enfin que tu me prennes beaucoup et ne me donnes presque rien. [1, c. 65].

Анафорический повтор передаёт чувство уверенности, надежду на позитивный исход событий:

Pour apprendre à aimer et tenter de guérir un enfant autiste, c'est beaucoup plus simple de l'imaginer comme un Petit Prince. Japprendrai ton langage. J'entrerai dans ton silence. J'oublierai ce que je crois savoir. Je t’aimerai. Te respecterai infiniment [1, c. 36].

Анафора, связанная с симметрией элементов в следующем примере звучит возвышенно-мажорно и придаёт фрагменту особую ясность и яркость:

Je sentis la présence qui grandissait en moi et me tenait la tête hors du Temps. Présence qui me fait traverser des fleuves de boue sans quej' m`enlise. Présence qui arme mon bras d`une épée. Présence terrible et exigeante qui pourrait bien ressembler, quand $j$ 'ai la tentation de lui donner un visage, au Moïse de Michel-Ange... [1, c. 62].

Ещё одну функцию анафоры - создание эффекта кульминации событий, можно проилюстрировать следующими примерами :

Te sortir de là. Te tirer de dessous ces pierres enchevêtrées. T`arracher à cette ville morte [1, c. 57].

Мать принимает осознанное, выстраданное решение бороться с болезнью своего ребёнка, методами найденными путем ежеминутного наблюдения за сыномаутистом.

Одновременное использование лексикограмматической контактной анафоры и анадиплосиса придаёт абзацу особый ритм, чётко, без лишних слов передаёт основную мысль автора - отныне именно она, мать ответственна за здоровье сына, пусть и в ущерб своей личной и творческой жизни:

Mais j'ai choisi. Je $T^{\prime} A$ l choisi. J'ouvre la fenêtre pour respirer comme avant d'affronter une douleur. J'ouvre la fenêtre pour évacuer tristesse, inquiétude, déchirement de ne plus avoir le temps d'écrire. Ne plus avoir le temps de réfléchir. Ne plus avoir le goût de respirer rien que pour moi [1, c. 57].

Je souffle sur ta vie. Je souffle sur tes doigts. Dans ton cou.C'est tout ce que je sais faire. Souffler. Souffler pour que la lueur minuscule qui s'allume parfois dans tes yeux ne s`éteigne pas [1, c. 65].

Следующий пример подчеркивает иконичность анафорического повтора, то как он передает продвижение вперёд от исходной точки [2, с. 46]:

Jean! Sylvestre! Écoute. J`t aime. Tu parleras. Tu mâcheras. Et à six ans, tu entreras au cours préparatoire de l’école du village. Je t'apprends les couleurs. Les odeurs. Je t'apprends à ne plus avoir peur [1, c. 57].

Автор пытается употребить минимум слов, максимально упрощенные конструкции, мать пытается говорить с сыном на его «языке»:

Mais du jour où j'ai fait taire ces pulsions de malheur et où j' t’ai regardé criant dans ton désert, je me suis servie de tout pour aller vers toi et que tu le sentes et le saches. Que tu me voies enfin. Je me suis servie de mes mains. De mes cheveux qui sont longs. De ma bouche. De ma langue. De l'esu tiède. De la douche. Du parfum. De Mozart. De mes bras. De mes larmes. De la mousse au chocolat. De ma force. De mon haleine. De mes dents [1, c. 57].

В следующем примере мы наблюдаем употребление автором рамочной конструкции совместно с контактной лексико-грамматической анафорой, что, безусловно, повышает эмоциональный накал повествования:

L'exil. L'exil en soi-même. Le double exil. Celui de l'écrivain. Celui de la mère d’un Petit Prince autiste qui veut sauver son enfant [1, c.78].

Лексико-грамматическая контактная анафора помогает автору создать эффект повторяющихся действий [4, с. 36]. Описания повседневной жизни ребёнка-аутиста, в течение дня повторяющего многократно одни и те же действия эмоционально воздействуют на читателя. В данном примере мы наблюдаем одну из основных функций анафоры: передача эффекта чередующихся событий:

Même le langage du sourire, tu ne l’acceptait pas. Tu criais quand on te souriait. Tu criait en te griffant le visage [1, c. 26].

De quoi me nourris-tu? De tes cris. Tu cries, et il faudrait que j’entende les oiseaux? Tu cries et je vois s`effilocher les premiers mots qui venaient si facilement. Tu cries et je vois s’ébouler ma pensée [1, c. 60].

Повторение личного местоимения «tu» в начале цепи предложений одного абзаца создаёт эффект доверительного разговора матери и сына. Мать рассказывает уже повзрослевшему сыну о тяжелых моментах, которые они вместе преодолели ценой невероятных усилий и самопожертвования.

Tu te griffes le visage. Tu n'es qu 'une boule de rage, complétement folle, que rien ne peut arrêter. Tu sanglotes. Et tu t’agites comme si tu voulais enlever un invisible vêtement, tout tissé d’orties. Tu ressembles à ces gens dont les habits brûlent et qui pour éteindre les flammes se roulent à terre en hurlant. Tu n`entends plus. Tu redoubles tes cris. Tu deviens fou [1, c. 19].

Comme toujours quand tu as fait un progrès je te serre dans mes bras et te dis que je suis heureuse. Comme toujours 
tu te retiens de sourire. $[1$, c.70].

Дистантная лексическая анафора, связанная с повторением словосочетания через несколько коротких предложений в следующем примере, как и другие фигуры прибавления, призвана создать эффект постоянства испытываемых чувств:

Il faudra aussi souffler sur ta vie. Mais qui soufflera sur la mienne? Chaque matin, je tente de renaître. J`essaie d’appeler le désir de vivre. De sauver. De continuer. D ‘aimer. $D$ 'espérer. Chaque matin, j’évacue la boue de mon cerveau [1, c. 59].

Сочетание в дистантной и контактной анафоры в одном абзаце создают мощный экспрессивный эффект:
$J$ 'aipeur. Je sens que mes forces diminuent. Mon énergie tout le camp. J'ai peur de ne plus pouvoir t’aimer. Je n’ai plus de réserves d’amour. Je t’en veux. Je t’en veux de saper ma vie à ce point $[1$, c. 80$]$.

Анафора, относясь к стилистическим фигурам упорядоченного повтора, содержит тождественные элементы и именно их положение в тексте и определяет стилистический эффект. Различные виды анафоры в сочетании с другими фигурами такими как анадиплосис, рамочная конструкция, к которым прибегает автор, служат средством для передачи оттенков эмоционального состояния главной героини автобиографического романа «Маленький принцканнибал».

\section{ЛИТЕРАТУРА}

1. Lefèvre F. Le petit prince cannibale/ F. Lefèvre. Actes Sud, Paris, 1990--103 p.

2. Балли Ш. Французская стилистика. — М., Издательство иностранной литературы, 1961. — 394 с.

3. Баранов А.Н., Паршин П.Б. Воздействующий потенциал варьирования в сфере метаграфемики // Проблемы эффективности речевой коммуникации: сборник научно-аналитических обзоров. М.: Ин-т науч. информ. по обществ. Наукам СССР, 1989. С. 41-115.

4. Береговская Э.М. Экспрессивный синтаксис. - Смоленск, СГПИ, 1984. - 92 с.

5. Матвеева Т.В. Учебный словарь: Русский язык, культура речи, стилистика, риторика.-М.: Наука; Флинта, 2003. - 432 с.

6. Москвин В.П. Выразительные средства современной русской речи: тропы и фигуры. Общая и частные классификации. Терминологический словарь. М.: Феникс, 2006. -944 с.

с Горелик Маргарита Алексеевна (ritagorelik@mail.ru), Новикова Елена Николаевна.

Журнал «Современная наука: актуальные проблемы теории и практики»

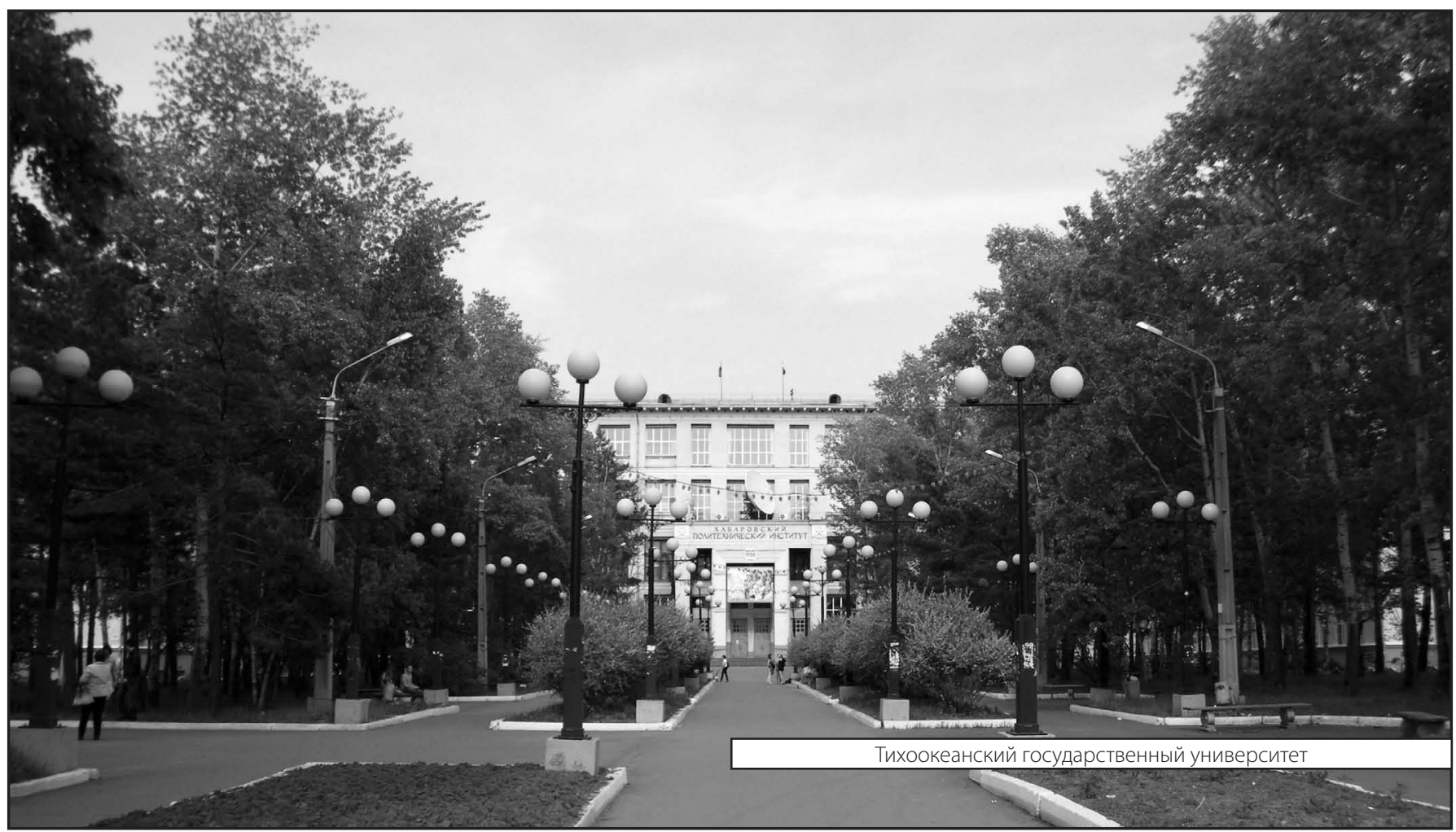

